ARTICLE

\title{
Important complications of chronic kidney disease
}

\author{
I van der Walt, ${ }^{1} \mathrm{MB} \mathrm{ChB}, \mathrm{MMed}$ (Int), Cert Nephrology (SA); C R Swanepoel, ${ }^{2} \mathrm{MB}$ ChB, MRCP (UK), FRCP (Edin); \\ B Mahala, ${ }^{3} \mathrm{MB}$ ChB, FCP (SA), MMed, Cert Nephrology (SA); A M Meyers, ${ }^{4}$ MB BCh, FCP (SA), Cert Nephrology (SA), FRCP (Lond) \\ ${ }^{1}$ Netcare Jakaranda Hospital, Pretoria, South Africa \\ ${ }^{2}$ Division of Nephrology and Hypertension, Department of Medicine, Faculty of Health Sciences, University of Cape Town, South Africa \\ ${ }^{3}$ Netcare Waterfall City Private Hospital, Johannesburg, South Africa \\ ${ }^{4}$ Donald Gordon Medical Centre, Klerksdorp Hospital, and National Kidney Foundation of South Africa, Johannesburg, South Africa
}

Corresponding author: A M Meyers (nkfsa@mweb.co.za)

The complications of chronic kidney disease (CKD) are dyslipidaemia, hyperkalaemia, metabolic acidosis, anaemia, and bone and mineral disorders. Dyslipidaemia may be treated with low-density lipoprotein-lowering agents. Statins are ineffective in stages 4 and 5 CKD, but are indicated for preventing the progression of disease in the earlier stages. Chronic acidosis has recently been shown to be a risk factor in the progression of CKD renal dysfunction. Therefore, treatment is mandatory. Practically, this should consist of $1-2$ heaped teaspoons of sodium bicarbonate 2 - 3 times per day, which is an inexpensive and safe therapy that does not raise the blood pressure in spite of the increased sodium level. Target levels of haemoglobin, according to international guidelines, are between $10 \mathrm{~g} / \mathrm{dL}$ and $12 \mathrm{~g} / \mathrm{dL}$. The serum phosphate level is raised in stage $4 \mathrm{CKD}$, and especially in stage $5 \mathrm{CKD}$, which is associated with coronary carotid and other vascular calcifications and may result in ischaemic heart disease, myocardial infarction and stroke. A raised parathyroid hormone level (secondary hyperparathyroidism) is also a major risk factor for cardiovascular disease and is associated with increased hypertension and resistance to the treatment of CKD-associated anaemia.

S Afr Med J 2015;105(4):321. DOI:10.7196/SAMJ.9536

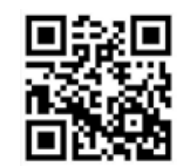

\section{Dyslipidaemia}

Chronic kidney disease $(\mathrm{CKD})$ is associated with alterations in lipoprotein structure and function, including:

- $\quad$ reduced high-density lipoprotein cholesterol

- increased intermediate-density lipoprotein

- increased proatherogenic lipid particles.

\section{Significance of dyslipidaemia control}

- Successful treatment of dyslipidaemia is known to lower cardiovascular disease (CVD) risk and should also retard the decline of kidney function.

- Since statins have been shown to decrease urinary protein or albumin excretion, they are recommended for CKD with proteinuria.

- Remarks on statin use in stages 3 - 5 CKD are given in Table 1.

- Concurrent use of statins and fibrates increases the risk of rhabdomyolysis.

\section{Target for low-density lipoprotein cholesterol}

- The Kidney Disease Outcomes Quality Initiative (KDOQI) guidelines recommend the following for dyslipidaemia therapy in CKD: in cases of low-density lipoprotein cholesterol (LDL-C) $<3.5 \mathrm{mmol} / \mathrm{L}$, the first step is lifestyle modification; in cases of LDL-C $>3.5 \mathrm{mmol} / \mathrm{L}$, drug therapy should be contemplated in addition to lifestyle modification, including diet therapy, weight control and exercise.

- It is essential that LDL-C be lowered to $\leq 1.8 \mathrm{mmol} / \mathrm{L}$.

\section{KDOQI guidelines for cholesterol lowering in CKD} patients (2013):

- Patients $>50$ years of age should receive a statin.

- Patients 18 - 49 years of age should receive a statin if another comorbidity is present.

- Kidney transplant recipients should receive a statin.

\section{Treatment of hyperkalaemia and metabolic acidosis \\ Hyperkalaemia}

- As CKD progresses in stage, acidosis and hyperkalaemia are observed. Hyperkalaemia is defined as a serum potassium level $\geq 5.5 \mathrm{mmol} / \mathrm{L}$. Hyperkalaemia $>7 \mathrm{mmol} / \mathrm{L}$ may potentially cause cardiac arrest; such cases should be treated as emergencies.

- If severe hyperkalaemia is observed, despite the absence of reduced kidney function, pseudohyperkalaemia, an artefact due to haemolysis of the blood specimen, should be considered.

- Hyperkalaemia is a risk factor for arrhythmias. In cases of severe hyperkalaemia, emergency levels should be confirmed by ECG abnormalities such as tenting T-waves, prolongation of PQ-times, followed by disappearance of the P-wave and widening of the QRS complex. Patients with life-threatening ECG findings, bradycardia and hypotension should be treated promptly, followed by treatment in conjunction with a nephrologist.

- Drug-induced hyperkalaemia in CKD is mostly caused by reninangiotensin-aldosterone inhibitors such as ACE inhibitors, angiotensin II receptor blockers (ARBs) and spironolactone or excessive intake of potassium-containing foods. Other causes include the administration of $\beta$-blockers, digoxin, nonsteroidal anti-inflammatory drugs (NSAIDs), trimethoprim or pentamidine.

- CKD caused by diabetic nephropathy may be associated with hyporeninaemic hypoaldosteronism, which may cause hyperkalaemia despite relatively well-preserved kidney function. This is known as type IV renal tubular acidosis.

\section{Emergency treatment}

- The first step is to stabilise the myocardium. The intravenous administration of calcium gluconate does not change plasma potassium, but transiently improves the ECG. The administration of calcium gluconate $20 \mathrm{~mL}$ intravenously over 1 minute can 
Table 1. Drugs for dyslipidaemia available in South Africa and cautionary remarks regarding their use in CKD

\begin{tabular}{|c|c|c|c|}
\hline Class & Generic name & Characteristics & Use in low GFR \\
\hline $\begin{array}{l}\text { 3-hydroxy-3-methyl- } \\
\text { glutaryl-CoA reductase } \\
\text { enzyme inhibitors } \\
\text { (statins) }\end{array}$ & $\begin{array}{l}\text { Pravastatin } \\
\text { Simvastatin } \\
\text { Fluvastatin } \\
\text { Atorvastatin } \\
\text { Rosuvastatin }\end{array}$ & $\begin{array}{l}\text { Inhibits cholesterol production } \\
\text { in the liver } \\
\text { Very effective to decrease TC, } \\
\text { LDL-C } \\
\text { Adverse reaction: liver damage, } \\
\text { rhabdomyolysis } \\
\text { Prolongs QT-interval on ECG }\end{array}$ & $\begin{array}{l}\text { Main excretory route is the bile duct, i.e. it can be used } \\
\text { in kidney damage (pravastatin is excreted mainly in the } \\
\text { urine) } \\
\text { Rhabdomyolysis may occur, although there is a low } \\
\text { incidence in CKD. In stages } 3 \text { and higher CKD, careful } \\
\text { follow-up is necessary } \\
\text { Cyclosporine, which is often used in resistant } \\
\text { nephrotic syndrome, may have adverse effects if used } \\
\text { simultaneously }\end{array}$ \\
\hline Anion exchange resins & $\begin{array}{l}\text { Cholestyramine } \\
\text { Colestimide }\end{array}$ & $\begin{array}{l}\text { Inhibits bile acid circulation } \\
\text { (intestine-liver) } \\
\text { Lowers TC, LDL-C }\end{array}$ & No problems \\
\hline Fibrates & $\begin{array}{l}\text { Bezafibrate } \\
\text { Fenofibrate }\end{array}$ & $\begin{array}{l}\text { Lowers TG (very effective) } \\
\text { Increases HDL-C } \\
\text { Rhabdomyolysis } \\
\text { Do not use with statins }\end{array}$ & $\begin{array}{l}\text { Do not use bezafibrate or fenofibrate in kidney failure or } \\
\text { dialysis patients } \\
\text { Do not use for stages } 4 \text { and } 5 \text { CKD }\end{array}$ \\
\hline Nicotinic acids & & $\begin{array}{l}\text { Lowers TG } \\
\text { Lowers Lp (a) } \\
\text { Rash on face }\end{array}$ & No problems \\
\hline Others & $\begin{array}{l}\text { Eicosapentaenoic acid } \\
\text { Ezetimibe }\end{array}$ & $\begin{array}{l}\text { Lowers TG } \\
\text { Antiplatelet function: anti- } \\
\text { atherosclerosis } \\
\text { Prevents absorption of } \\
\text { cholesterol }\end{array}$ & No problems \\
\hline
\end{tabular}

be repeated if there is no improvement in the ECG within $3-5$ minutes.

- The second step is to shift the potassium from the extracellular to the intracellular compartment to try to rapidly decrease the serum potassium level. This can be done in three different ways:

- Intravenous insulin combined with glucose. Administer $10 \mathrm{U}$ short-acting insulin combined with $50 \mathrm{~mL}$ of $50 \%$ dextrose as a bolus, followed by an intravenous infusion of $5 \%$ dextrose to prevent hypoglycaemia.

- $\boldsymbol{\beta}_{2}$-agonist. Administer $20 \mathrm{mg}$ salbutamol, a $\beta_{2}$-agonist, by inhalation over 10 minutes, with onset of action approximately 30 minutes. (This is not usually required.)

- Sodium bicarbonate in CKD patients who are not yet on dialysis. Bicarbonate administration can lower serum potassium by enhancing renal potassium excretion. The effect is very slow and not of use in an acute situation unless the patient has severe metabolic acidosis that needs bicarbonate treatment.

- Once the previous temporary measures have been performed, further interventions are undertaken to remove potassium from the body.

- Loop diuretics are only successful in patients with adequate kidney function.

- The resin exchanger sodium polystyrene sulphonate (Kexelate) removes potassium from the blood into the gut in exchange for an equal amount of sodium. It is slow acting and the plasma potassium only starts decreasing within $1-2$ hours. It can be given orally or as a retention enema. The amount given varies from $30 \mathrm{~g}$ to $60 \mathrm{~g}$. This can be repeated, but tends to cause constipation.
- Haemodialysis is the treatment of choice for patients with advanced $\mathrm{CKD}$ and severe hyperkalaemia.

\section{Prevention}

- Dietary counselling on potassium restriction.

- Avoid medications that interfere with renal excretion of potassium, e.g. potassium-sparing diuretics, NSAIDs, ACE inhibitors, ARBs.

- Avoid drugs that interfere with potassium shifts from the intracellular to the extracellular compartments, e.g. non-selective $\beta$-blockers.

- In selected patients with sufficient residual kidney function treatment with a loop diuretic may be used to stimulate urinary potassium excretion.

\section{Metabolic acidosis}

Metabolic acidosis is characterised by:

- low arterial blood $\mathrm{pH}$ (acidaemia) $(<7.35)$

- reduced serum $\mathrm{HCO}_{3}^{-}$concentration

- decreased $\mathrm{pCO}_{2}$ (from respiratory compensation).

\section{Systemic effects}

Metabolic acidosis may lead to a variety of changes in tissues and organs, e.g.:

- cardiovascular changes such as tachycardia, bradycardia, hypotension and cardiac failure

- life-threatening hyperkalaemia

- nausea, vomiting and abdominal pain

- confusion, with depression of the central nervous system.

The associated symptoms and signs will depend on the rate and magnitude of fall in the $\mathrm{pH}$ and of the underlying pathology. 


\section{Uraemic acidosis}

Metabolic acidosis occurs in renal failure owing to a decreased ability to excrete $\mathrm{H}^{+}$or an inability to produce ammonia.

In the early stages of CKD (GFR $<40 \mathrm{~mL} / \mathrm{min}$ ), metabolic acidosis with a normal anion gap (AG) may become evident. As CKD progresses (GFR $<20 \mathrm{~mL} / \mathrm{min}$ ), a high $\mathrm{AG}$ metabolic acidosis may result.

In advanced CKD, an increased AG is typical owing to the presence of retained acids such as sulphates, phosphates, urate and hippurate.

\section{Treatment principles}

Patients with metabolic acidosis are often very ill and their condition tends to deteriorate rapidly.

The routine administration of sodium bicarbonate is controversial, although it needs to be done to correct severe acidosis.

The potential complications of sodium bicarbonate administration include volume overload, especially in patients with renal or cardiac function impairment, hypernatraemia, hypokalaemia, hypocalcaemia and alkalosis.

The amount of bicarbonate required $(\mathrm{mmol})$ can be estimated as follows:

target plasma $\mathrm{HCO}_{3}^{-}(\mathrm{mmol} / \mathrm{L})$ - current plasma $\mathrm{HCO}_{3}^{-}(\mathrm{mmol} / \mathrm{L})$ $\times 40 \%$ body weight $(\mathrm{kg})$.

\section{Anaemia in CKD}

Anaemia is the most common complication of CKD and is associated with greatly reduced quality of life. Successful treatment of anaemia in renal disease may reduce the decline of kidney function. The target haemoglobin levels are $10-12 \mathrm{~g} / \mathrm{dL}$ when treating anaemia in CKD. The treatment is costly and therefore rational consideration is mandatory.

\section{Renal anaemia}

Renal anaemia is typically normochromic normocytic. It is caused mainly by the impaired production of erythropoietin by the kidney and partly by uraemic toxins. Other causes that may play a role in $\mathrm{CKD}$, especially in dialysis patients, are:

- erythropoietin resistance (most significant)

- bone marrow toxins (none has been isolated yet)

- bone marrow fibrosis, secondary to hyperparathyroidism

- ongoing inflammatory processes, e.g. untreated infections

- haematinic deficiency (iron, folate and vitamin $\mathrm{B}_{12}$ )

- increased red cell destruction

- abnormal red cell membranes, causing increased osmotic fragility

- increased blood loss from occult gastrointestinal bleeding and blood sampling and during haemodialysis

- ACE inhibition.

Erythropoietin is a glycoprotein hormone that stimulates red cell production by binding to erythropoietin receptors, located on early erythroid progenitor cells in the bone marrow.

The binding of erythropoietin to these progenitor cells saves them from apoptosis and therefore permits cell division and maturation into red cells. In CKD, the erythropoietin levels may be normal, but inadequate for the degree of anaemia. The mechanisms impairing erythropoietin production in diseased kidneys remain poorly understood. Inhibition of erythropoiesis by uraemic inhibitors is also possible and may contribute greatly to the anaemia of CKD; such factors have not been identified. Dialysis can improve renal anaemia and the efficacy of erythropoietin-stimulating agents. Patients with renal disease may develop chronic infections and other chronic diseases. Chronic disease contributes to anaemia in such cases. The anaemia of chronic disease is mediated by inflammatory cytokines through the inhibition of erythropoietin production and efficacy and reduced iron availability.

Hepcidin is the key mediator of iron metabolism. In inflammatory states hepcidin blocks iron absorption in the gut and promotes iron sequestration in macrophages.

\section{Other causes}

Anaemia associated with CKD is most likely renal anaemia; however, the differential for other diseases must be considered true for stages 1 - 3 CKD

The evaluation of anaemia in CKD patients should include a complete blood count with red cell indices (mean corpuscular haemoglobin concentration, mean corpuscular volume). Renal anaemia is usually normochromic and normocytic. Vitamin $\mathrm{B}_{12}$ and folate deficiency may lead to macrocytosis, while iron deficiency or inherited disorders of haemoglobin may produce microcytosis. Iron studies should be performed to assess the level of iron in tissue stores or the adequacy of iron supply for erythropoiesis.

Anaemia may signify the presence of malnutrition or systemic illness. It is an independent risk factor for hospitalisation, CVD and mortality. ACE inhibitors can exacerbate anaemia.

\section{Treatment of anaemia protects the heart}

Anaemia exacerbates heart failure. Treatment of anaemia is beneficial for life expectancy and can also improve the prognosis of CVD. The quality of life is improved for those with a haemoglobin level within the target range.

\section{Target level of haemoglobin}

The Kidney Disease Improving Global Outcome (KDIGO) guidelines state that the haemoglobin level should range from $10.0 \mathrm{~g} / \mathrm{dL}$ to $12 \mathrm{~g} / \mathrm{dL}$ in CKD patients on dialysis. Pre-dialysis levels should be at $10 \mathrm{~g} / \mathrm{dL}$.

\section{Role-sharing between nephrologists and primary care physicians}

Early referral to a nephrologist is advisable. Once the treatment strategy has been decided, nephrologists and primary care physicians continue management in partnership.

\section{Evaluation of iron deficiency}

Evaluation of the iron deficit and correct iron supply is important in the treatment of anaemia. Anaemia may improve with the administration of iron supplements, even when the patient is not apparently iron deficient, as the use of recombinant erythropoietin may cause relative iron deficiency.

The KDOQI guidelines for recombinant human erythropoietin in CKD are:

- serum ferritin $>100 \mathrm{ng} / \mathrm{mL}$ before dialysis

- serum ferritin $>200 \mathrm{ng} / \mathrm{mL}$ in dialysis patients

- transferrin saturation $>20 \%$.

Iron can be given either intravenously or orally. Intravenous iron is more efficacious, especially for dialysis patients and those on erythropoietin treatment.

\section{Use of exogenous erythropoietins}

There are currently a number of erythropoietin-stimulating agents available, including older, shorter-acting drugs and new, longer-acting ones. The appropriate agent and dose depend on a number of factors, 
including cost, efficacy and convenience. As these drugs are expensive and have side-effects, their management is best left to a nephrologist.

\section{Bone and mineral disorders}

Hyperphosphataemia is the key abnormality that sets off a cascade of metabolic events, resulting in bone mineral density of CKD.

Phosphate is retained as renal function deteriorates - much the same as creatinine is retained. This retention becomes obvious as stage $3 \mathrm{~b}$ CKD is reached. It will progressively worsen as end-stage is approached and must be lowered to within normal limits.

A high phosphate diet stimulates osteocytes to produce fibroblast growth factor 23 which, in turn, inhibits the hydroxylation of vitamin $\mathrm{D}$ to active 1,25 vitamin $\mathrm{D}_{3}$. Without vitamin $\mathrm{D}_{3}$, calcium absorption and bone remodelling are decreased. The resultant hypocalcaemia is a major stimulus for parathyroid hormone (PTH) release, with the consequent development of renal bone disease. Serum alkaline phosphatase is a marker of increased bone turnover. Therefore, high blood levels show PTH activity.

Of note, both hyperphosphataemia and vitamin $\mathrm{D}_{3}$ deficiency result in increased PTH secretion.

Initially the stimulus for PTH secretion may be controlled by increasing the serum calcium, reducing the phosphate levels in the blood and prescribing vitamin $\mathrm{D}_{3}$. This is the secondary hyperparathyroidism stage (Table 2). However, with time and uncontrolled, prolonged stimulation of PTH secretion, the parathyroid hormones become autonomous and the stage of autonomous hyperparathyroidism is reached (Table 3). Parathyroidectomy may now be necessary or expensive calcimimetic drugs must be administered to try to restore the disordered metabolic environment.

There is uncertainty about the interpretation of vitamin $\mathrm{D}_{3}$ level measurements. If they are to be measured, then $25-\mathrm{OH}$-vitamin $\mathrm{D}_{3}$ levels are recommended for assessment.

Table 2. Diagnosis of secondary hyperparathyroidism*

\begin{tabular}{ll}
\hline Serum biochemistry & Normal range \\
\hline Calcium & Below or low normal range \\
Phosphate & High
\end{tabular}

${ }^{*}$ PTH 2 - 9 times the normal range (check with the laboratory which assay and normal range) and low vitamin $\mathrm{D}_{3}$ levels: measure $25-\mathrm{OH}$-vitamin $\mathrm{D}_{3}$.

Table 3. Autonomous hyperparathyroidism ${ }^{*}$

\begin{tabular}{ll}
\hline Serum biochemistry & Normal range \\
\hline Calcium & Higher or high normal range \\
$\begin{array}{l}\text { Phosphate } \\
\text { * } \mathrm{PTH}>2-9 \text { times the normal range (check with the laboratory which assay and } \\
\text { normal range). }\end{array}$
\end{tabular}

\section{Therapy}

The steps for therapy are shown in Table 4 . Non-calcium-containing phosphate binders are recommended when there is significant metastatic calcification and/or when hypercalcaemia is present.

Calcimimetics, which sensitise the parathyroid glands to serum calcium, are useful to prescribe in hyperparathyroidism when the serum PTH levels are high (2 - 9 times above the normal range - check with the laboratory for normal ranges). They have a role to play in diminishing PTH levels in any of the clinical situations that occur in CKD.

\section{Follow-up blood measurements}

These are given in Table 5 .

These follow-up times are guidelines only and the tests should be performed more frequently if there are significant abnormalities.

\section{Special points to note}

- Involve a nephrologist early in the course of CKD.

- Avoid over-suppression of the parathyroid glands, as this will lead to dynamic bone disease.

- The exact PTH level at which secondary and autonomous hyperparathyroidism is diagnosed is uncertain, because of varying assays. The biochemistry, as outlined above (together with radiographs of bones), must then be used to assist in the diagnosis.

- Be aware of trends in serum alkaline phosphatase levels; the level may be in the normal range but may have doubled from the previous reading.

- Osteoporosis accompanies bone disease that occurs in CKD. Bisphosphonates must not be used in stages 3 - 5 CKD patients.

Table 4. Steps for therapy

\begin{tabular}{lll}
\hline Steps & Stages 3 - 4 CKD & Stages 5 - 5d CKD \\
\hline $\begin{array}{l}\text { Lower the } \\
\text { serum } \\
\text { phosphate }\end{array}$ & $\begin{array}{l}\text { Calcium carbonate or } \\
\text { non-calcium-containing } \\
\text { phosphate binders, e.g. } \\
\text { lanthanum carbonate or } \\
\text { sevelamer carbonate }\end{array}$ & $\begin{array}{l}\text { Calcium carbonate or } \\
\text { non-calcium-containing } \\
\text { phosphate binders, e.g. } \\
\text { lanthanum carbonate or } \\
\text { sevelamer carbonate }\end{array}$ \\
$\begin{array}{l}\text { Increase } \\
\text { the serum } \\
\text { calcium }\end{array}$ & $\begin{array}{l}\text { First administer calcium } \\
\text { carbonate, then vitamin } \mathrm{D}_{3}\end{array}$ & $\begin{array}{l}\text { First administer calcium } \\
\text { carbonate, then vitamin } \mathrm{D}_{3}\end{array}$ \\
\end{tabular}

Table 5. Follow-up blood measurements

\begin{tabular}{|c|c|c|}
\hline Stage CKD & 3-monthly & 6-monthly \\
\hline 3 & - & $\begin{array}{l}\text { Calcium and phosphate } \\
\text { levels }\end{array}$ \\
\hline 4 & $\begin{array}{l}\text { Calcium, phosphate and } \\
\text { alkaline phosphatase levels }\end{array}$ & $\begin{array}{l}\text { PTH levels } \\
\text { 25-OH-vitamin } \mathrm{D}_{3}\end{array}$ \\
\hline 5 & $\begin{array}{l}\text { Calcium, phosphate and } \\
\text { alkaline phosphatase levels }\end{array}$ & $\begin{array}{l}\text { PTH levels } \\
\text { 25-OH-vitamin } \mathrm{D}_{3}\end{array}$ \\
\hline
\end{tabular}

